\title{
WhatsApp na educação superior: uma experiência de aprendizagem colaborativa
}

\author{
Sheilla Silva da Conceição ${ }^{1}$, Henrique Nou Schneider ${ }^{2}$ \\ ${ }^{1}$ Programa de Pós-Graduação em Educação (PPGED) - Universidade Federal de \\ Sergipe (UFS) - São Cristóvão - Sergipe - Brasil. \\ ${ }^{2}$ Departamento de Ciência da Computação - Programa de Pós-Graduação em Educação \\ (PPGED) Universidade Federal de Sergipe (UFS) - São Cristóvão - Sergipe - Brasil. \\ sheillaconceicao@gmail.com, hnseterra.com.br
}

\begin{abstract}
Resumo. $O$ artigo objetiva relatar a experiência do uso da rede social WhatsApp no processo de ensino e aprendizagem dos conteúdos propostos pela disciplina políticas públicas e planejamento escolar. É uma pesquisa qualitativa do tipo intervenção da prática pedagógica. $O$ desenvolvimento do artigo provém das discussões dos conteúdos abordados no ciclo de seminários proposto pela professora da disciplina. A cada seminário o grupo responsável pela apresentação dava início ao debate no whatsApp e os outros alunos continuavam as discussões até dois dias antes da próxima apresentação. Constatou-se que neste processo de discussão no aplicativo houve uma aprendizagem colaborativa de forma prazerosa e interativa.
\end{abstract}

Palavras-chave: Educação. WhatsApp. Aprendizagem Colaborativa.

Abstract. The present article aims to report the experience of using the social networking - WhatsApp in the teaching and learning of the contents proposed by the public policy and school planning discipline. It is a qualitative research based on an intervention of pedagogical practice. The development of the article comes from the contents of discussions treated during the seminar series proposed by the teacher of the discipline. Each seminar presented by the group was responsible for presenting a debate on WhatsApp and other students continued discussions until two days before the next presentation. It was also found that during the discussion process about the application there was a collaborative learning on an enjoyable and interactive way.

Keywords: Education. Whatsapp. Collaborative Learning.

\section{Introdução}

Neste século, com as novas invenções tecnológicas, principalmente aquelas voltadas para a disseminação da informação e facilitação da comunicação com apoio da internet, o processo educativo sofreu uma evolução significativa que reflete não apenas nas instituições de ensino, mas em toda sociedade. Novos espaços e tempos de aprendizagem estão surgindo e tornando dinâmicos e significativos o ensinar e o aprender. As evoluções socioculturais e tecnológicas geram incessantes mudanças nas 
organizações e no pensamento humano. Isso exige independência, criatividade e autocrítica na obtenção e na seleção de informações, assim como na construção do conhecimento.

No universo da grande teia mundial de computadores "internet", o uso das redes sociais online ${ }^{1}$ são cada vez mais comuns, desde os mais jovens aos mais velhos, que estão se inserindo com uma grande frequência nesses meios. É fato que os usuários dessas comunidades virtuais as utilizam mais frequentemente para diversão e entretenimento, mas principalmente para se comunicar e interagir. A educação, especificamente, a escolar, não pode ficar a mercê desse potencial e precisa rever as suas práticas pedagógicas na atual sociedade da informação e comunicação.

A utilização da internet na educação faz acreditar numa nova dimensão cognitiva e social na relação de ensino e aprendizagem. No ensino porque o docente terá novos recursos para tornar sua aula mais atrativa e participativa, e na aprendizagem pela oportunidade que os alunos terão de buscar novas fontes e espaços para a construção do conhecimento. "A aprendizagem é, sem dúvida, um processo complexo que envolve fatores sensório-motores, neurológicos, afetivos, emocionais, linguísticos, cognitivos, comportamentais, ambientais e interacionistas". (SANTAELLA, 2013, p. 289).

Os principais agentes do processo educativo, professores e alunos, devem andar "antenados" nas transformações dessa sociedade. Por um lado, os docentes, aprendendo a aprender, apropriando-se e inserindo na sua metodologia de trabalho as tecnologias digitais da informação e comunicação, aquilo que encanta e atrai os discentes e promove uma maior interação. Não se entenda a interação como um mero processo de troca, mas como um processo dialético de interferências e de produção de mudanças mútuas. Os recursos tecnológicos se hibridizam cada vez mais, e as tecnologias móveis e mídias locativas como campo múltiplo disponível em muitas versões vêm, dependendo do modo como são operadas e dos usos que lhes são agregados, alterar a forma de repensar o espaço e lugar no cotidiano das pessoas. André Lemos (2008), esclarece e explica a constituição e abrangência das mídias locativas (locative media) no seu atual estado da arte e define como um "dispositivo informacional digital cujo conteúdo está ligado a uma localidade [/objeto]” (LEMOS, 2008, p. 207).

Trata-se de processos de emissão e recepção de informação a partir de um determinado local que implica uma relação entre lugares e dispositivos móveis digitais até então inédita. Pode-se inferir que as mídias locativas e tecnologias móveis podem favorecer a construção colaborativa do conhecimento, a partir do trabalho conjunto entre professores-alunos e alunos-alunos, próximos sejam presencial ou virtualmente. Tal aspecto pode possibilitar a participação em pesquisas em tempo real, de um projeto entre vários grupos, de uma investigação sobre um problema de atualidade. Uma forma de se trabalhar colaborativamente é criar um grupo no WhatsApp com os alunos ou no Facebook, como espaços de referências, onde estes vão construindo e colocando o que acontece de mais importante nas aulas; os textos, os endereços, as análises, as pesquisas, os anseios, as dúvidas, as descobertas, enfim uma verdadeira teia de

1 É um processo de socialização, algum tipo de interação coletiva e social, presencial ou virtual, que pressupõe a partilha de informações, conhecimentos, desejos e interesses". (FRANCO, 2012, p. 117) 
V Congresso Brasileiro de Informática na Educação (CBIE 2016)

Anais dos Workshops do V Congresso Brasileiro de Informática na Educação (CBIE 2016)

informações que poderá contribuir na construção e reconstrução de novas ideias e, possivelmente, gerar conhecimentos novos.

\section{A formação do professor para o uso das redes sociais no processo de aprendizagem.}

O que é ser professor hoje? É viver intensamente o seu tempo, conviver; é ter consciência e sensibilidade. Não se pode imaginar um futuro para a humanidade sem educadores, assim como não se pode pensar num futuro sem seres com formação humana segundo uma visão rousseauniana (transformar novos seres humanos em futuros cidadãos). Segundo Paulo Freire (1983), numa visão emancipadora, consciência crítica e não ingênua, os educadores não só transformam a informação em conhecimento e em consciência crítica, mas também formam pessoas. Eles fazem fluir o saber (não o dado, a informação e o puro conhecimento), porque constroem sentido para a vida das pessoas e para a humanidade; e buscam, juntos, um mundo mais justo, mais produtivo e mais saudável para todos.

Vive-se em uma sociedade onde as tecnologias têm afetado vários aspectos da vida, gerando novos instrumentos que aceleram a comunicação, transformam a produção, as relações dos homens entre si e com suas atividades e, dessa forma, a própria organização da sociedade. Tais acontecimentos produzem efeitos sociais que merecem a atenção da escola, de seus profissionais e do estado enquanto instituição mantenedora do ensino de qualidade. Os ambientes virtuais de aprendizagem também são espaços que podem possibilitar uma ampla interação entre professor, aluno e material; bem como a aprendizagem colaborativa, Kenski (2012) afirma que:

As tecnologias ampliam as possibilidades de ensino para além do curto e delimitado espaço de presença física de professores e alunos na mesma sala de aula. A possibilidade de interação entre professores, alunos, objetos e informações que estejam envolvidos no processo de ensino redefine toda a dinâmica da aula e cria novos vínculos entre os participantes. Paradoxalmente, o uso adequado das tecnologias em atividades de ensino a distância pode criar laços e aproximações bem mais firmes do que as interações que ocorrem no breve tempo da aula presencial. (KENSKI, 2012, p. 88)

Diante destas mudanças no cotidiano, a educação pode e deve interferir e interagir no processo de integração e difusão das tecnologias, visando à transformação das relações sociais, no sentido de que elas sejam mais justas e mais democráticas. Para isso, é preciso pensar em uma educação que forme cidadãos capazes de lidar com o avanço tecnológico, participando dele e de suas consequências, influenciando e contribuindo na construção do mundo que desejarem.

O grande desafio hoje para o professor é a apropriação, no contexto formativo, das ferramentas digitais, seguido do reconhecimento das possibilidades de uso pedagógico. Atualmente as redes sociais são consideradas como espaço virtual de interação que pode se tornar um ambiente favorável ao processo de ensino e aprendizagem, tanto para a formação de professores como de alunos. (SALES e FICHMANN, 2013, p.2) 
Na maioria das vezes, porém, a escola não considera estes importantes aspectos da vida atual e, no que diz respeito a seus objetivos e métodos, não trabalha com as diferentes fontes de aquisição de conhecimento. Para cumprir seu papel social, a escola não pode ignorar as tecnologias da informação e da comunicação ou entrar em conflito com elas e continuar utilizando uma linguagem distante da realidade dos alunos. Em pesquisa realizada sobre iniciativas de aprendizagem móvel por meio de tecnologias móveis Nascimento e Castro Filho (2015) constataram que

Os resultados revelaram que o iPod touch foi usado para apoiar a aprendizagem do conteúdo de línguas, fornecer apoio pedagógico diferenciado e ampliar o tempo de pesquisa com atividades realizadas em casa. No entanto, alguns desafios foram identificados, tais como: necessidade de formação profissional e pessoal de suporte técnico (NASCIMENTO; CASTRO FILHO, 2015, p. 725)

A pesquisas realizada pelos autores Nascimento e Castro Filho (2015) apresentam resultados positivos com o uso das tecnologias móveis, todavia os próprios autores levantam algumas inquietações que são relevantes apresentar:

O que ocorre durante o processo de aprendizagem móvel está sendo também trabalhado e relacionado ao contexto escolar que ultrapasse os muros da escola, ou seja, como o professor pode mediar práticas colaborativas com dispositivos móveis no contexto da sala de aula em situações presentes no dia a dia do aluno? (NASCIMENTO; CASTRO FILHO, 2015, p. 729)

Nas representações culturais e educacionais, normalmente não se discutem a produção de conteúdos numa perspectiva de colaboração, autoria e coautoria dos sujeitos. A educação tornou-se estratégica para o desenvolvimento, mas, para isso, não basta "modernizá-la", será preciso transformá-la profundamente. Nesse processo, tornase preponderante a formação do professor para o uso significativo das tecnologias digitais e móveis. O professor inovador e as instituições de ensino necessitam fazer uma reestruturação curricular, elaborar seus parâmetros curriculares, enfim, ser cidadã.

Uma diversidade de cursos oferecidos, com diferentes focos, explorando a utilização de diferentes softwares e outros recursos educacionais digitais, contribui de forma significativa para que o professor conheça diferentes estratégias didáticas com a utilização das TIC em sala de aula. Ademais, a cada dia, novas ferramentas e possibilidades pedagógicas com as TIC são desenvolvidas. Isto reforça a necessidade de existir cada vez mais cursos, sobretudo de formação continuada, com diferentes ferramentas e conteúdos, que oportunizem novos possibilidades ao professor para ministrar suas aulas. (LIMA; LIMA; MAIA, 2015, p. 438)

Tudo muda muito rápido, valores se desfazem e/ou se modificam, dissolvem-se fronteiras e desenraizam-se as coisas, as pessoas e as ideias, trazendo com isso diferentes implicações sociais em que emergem novas formas de participação dos cidadãos, bem como se busca sensibilizá-los, cada vez mais, para questionar, intervir e buscar de forma autônoma a apropriação das novas ferramentas tecnológicas. O que muda no papel do professor? Muda a relação de espaço, tempo e comunicação com os alunos. O espaço de trocas aumenta da sala de aula para outros espaços. O tempo de enviar ou receber informações se amplia para qualquer dia e hora da semana. É um 
papel que combina alguns momentos do professor convencional - às vezes é importante dar uma bela aula expositiva - com mais momentos de gerente de pesquisa, de estimulador de busca, de coordenador de processos e dos resultados. É um papel de animação e coordenação muito mais flexível e constante, que exige muita atenção, sensibilidade, intuição e domínio tecnológico.

Diante da inovação tecnológica no ensino faz-se mister trabalhar colaborativamente a fim de que os alunos ampliem seus conceitos de mundo e melhor se relacionem com o professor e seus colegas. Por meio do trabalho em grupo presencial ou online, o aluno pode gradativamente, aprender a fazer correlações e extrair conclusões a partir dessas, posicionando-se como sujeito, participando ativamente de um diálogo contínuo com diversos textos, com outros leitores e com diferentes áreas do conhecimento.

A aprendizagem colaborativa, que acontece com duas ou mais pessoas, exige um formador que possua um perfil diferente do professor que tem atuado há décadas. Os professores e alunos poderão compartilhar os recursos materiais e informacionais de que dispõem. Professores e alunos aprendem juntos, interagindo por meio de discussões e ações compartilhadas. Nesse sentido, o professor é aquele quem provoca e media o processo educativo para que o educando aprenda a pensar. De acordo com Torre e Irala,

O aprender "em conjunto" pode ser interpretado de diversas maneiras, como situações de aprendizagem presenciais ou virtuais, síncronas ou assíncronas, esforço totalmente em conjunto ou com divisão de tarefas. Assim sendo, a prática de aprendizagem colaborativa pode assumir múltiplas caracterizações, podendo haver dinâmicas e resultados de aprendizagem diferentes para cada contexto específico (TORRE; IRALA, 2014, p.65).

Deste modo, e partindo do princípio que a educação se dá em todos os espaços humanos e as tecnologias contribuem para as mudanças de paradigma em todos os espaços de aprendizagem, as mídias locativas e tecnologias móveis adentram aos espaços formais de instrução educativa, promovendo mudança no paradigma de ensino e aprendizagem, transformando estes espaços, alterando aspectos culturais e tradicionais, exigindo do agente formador adaptação ao paradigma convergente.

\section{Metodologia}

O trabalho aqui apresentado é uma pesquisa qualitativa em que os dados serão analisados conforme Trivinos (1987) em toda sua riqueza descritiva. É do tipo pesquisa participante a partir da própria prática de ensino. Essa pesquisa é um instrumento de trabalho na construção do conhecimento que tem como objetivo compreender, intervir e transformar a realidade. Para Brandão e Streck (2008) a pesquisa participante oferece um repertório de experiências destinadas a superar a oposição pesquisador e pesquisado no interior dos processos de produção coletiva do saber, visando a seguir ações transformadoras.

Parte da experiência com o uso do WhatsApp no processo de aprendizagem da disciplina Políticas Públicas e Planejamento Escolar realizado no segundo semestre de 2015 com carga horária de quarenta horas com duas horas aula por semana. A turma 
composta de vinte e oito alunos de primeiro ao quarto períodos dos cursos de Pedagogia (vinte e três alunas); letras (uma aluna) e Serviço Social (quatro alunos). A proposta surgiu por perceber que poderia agregar valor na aprendizagem dos conteúdos tratados nas aulas e cuja intenção era, também, de no semestre seguinte propor a esses alunos, a partir da disciplina "Aprendizagem e novas tecnologias na educação" utilizar as tecnologias móveis nos processos de aprendizagem dos alunos da educação básica em escolas públicas do município.

Para realização da pesquisa, a qual foi pensada na atuação ética e compromissada com a turma, foi proposto aos alunos e aceito por todos de forma receptiva o uso do WhatsApp na sala de aula e fora dela. No primeiro momento foi explicado toda a proposta de forma detalhada, ou seja, as discussões no WhatsApp darse-ia a cada tema inicialmente abordado em sala de aula e agregado ao I Ciclo de Seminários criado pela professora regente sobre os conteúdos das disciplinas para uma melhor e mais significativa discussão em sala de aula e no ambiente virtual. No segundo momento foram formados quatro grupos com cinco pessoas e dois grupos com quatro pessoas, totalizando os vinte e oito alunos da turma da disciplina "políticas públicas e planejamento na educação básica". Cada grupo ficou responsável em estudar e trazer em formato de seminários a discussão de um tema, os quais foram selecionados pela professora: "o processo de ensino na escola"; "A aula como forma de organização do ensino"; "o planejamento escolar"; "Re-significando a prática do planejamento "processo de planejamento" e "modelo de plano". Em cada seminário temático apresentado e discutido com a turma, o grupo responsável pelo tema, em dois dias antes da apresentação postava no grupo do WhatsApp o resumo do texto que iria apresentar para que os colegas da turma começassem a interagir na discussão do tema abordado pela equipe. Após finalização dos seminários a professora regente solicitou a todos os alunos que respondessem a um questionário sobre a impressão dos resultados do processo de aprendizagem dos conteúdos através dessa metodologia de ensino. Para isso, disponibilizou um $\operatorname{link}^{2}$ de um formulário feito no google drive, no grupo do WhatsApp da turma da disciplina. As conversas e imagens foram exportadas por e-mail para fazer as respectivas análises.

\section{Resultados}

Os alunos da disciplina Políticas Públicas e Planejamento Escolar atenderam a proposta da professora que foi a de promover a aprendizagem colaborativa por meio do ciclo de seminários e o uso do aplicativo WhatsApp para a discussão dos temas abordados. Os alunos dialogavam entre si, posicionando sobre as descobertas diante das leituras realizadas nas discussões dos temas. Vale ressaltar que as apresentações dos seminários, que serviram como ponto inicial para discussão no grupo do WhatsApp, foram preponderantes para a interação entre os colegas da turma. Alguns grupos convidaram pessoas externas à faculdade para palestrar sobre o tema proposto pela professora. Mas

\footnotetext{
${ }^{2}$ https://docs.google.com/forms/d/e/1FAIpQLSe_RN7_NeO98YE6Q-

c2nMkZxqL9QaS_hvc4yS0_sjCDVJSuDg/viewform?usp=send_form\#start=openform
} 
V Congresso Brasileiro de Informática na Educação (CBIE 2016)

Anais dos Workshops do V Congresso Brasileiro de Informática na Educação (CBIE 2016)

mesmo trazendo um palestrante, o grupo apresentava o tema mostrando sua compreensão acerca do assunto. Seguem algumas das conversas sobre os temas abordados no ciclo de seminários e extensão da discussão pelo WhatsApp.

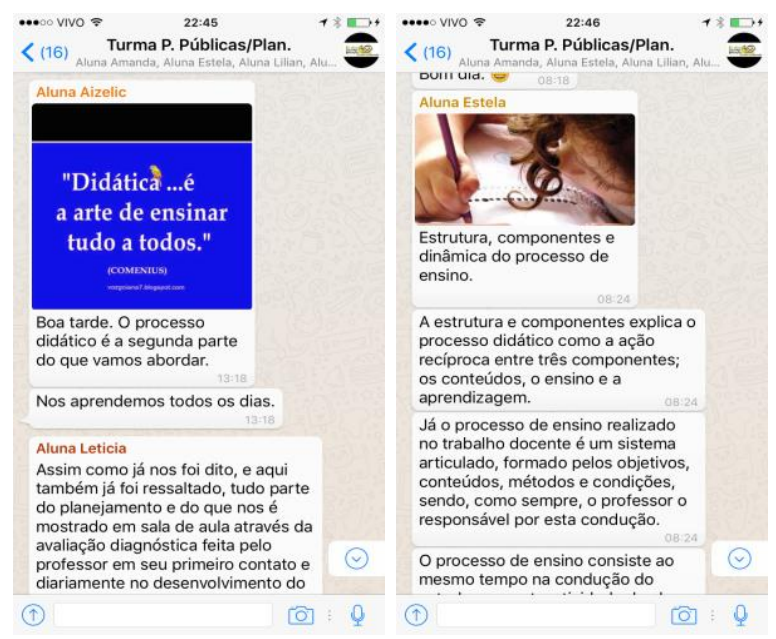

Figura 1. Conversas dos alunos no WhatsApp sobre o tema abordado.

As conversas realizadas mostraram o quão foi significativa a prática do seminário agregada a rede social WhatsApp devido a forma de extensão do espaçotempo para as discussões além do espaço físico. Essa percepção deve-se ao limitado tempo nesse espaço que não permite discussões maiores. Sem contar que há alunos tímidos em falar em público.

O uso do WhatsApp colabora no processo de ensino e aprendizagem, visto que a troca de informações é quase em tempo real. Esse tipo de comunicação é importante, e colabora tanto à $\mathrm{EaD}$ quanto ao ensino presencial, já que o aluno pode fazer questionamentos ao professor a qualquer momento, não sendo necessário o contato pessoalmente. (ALENCAR; PESSOA, SANTOS; CARVALHO; LIMA, 2015, p. 791)

Vale ressaltar que as apresentações no ciclo de seminários foram seriamente organizadas pelos grupos que se empenharam em fazer o melhor possível. As aulas se tornaram prazerosas e reflexivas. Ao término das aulas os alunos dos outros grupos logo se posicionavam diante das apresentações acontecidas naquela noite. Assim as tecnologias móveis por meio de seus aplicativos podem ser utilizadas por professores nas práticas pedagógicas. A facilidade de comunicação, trazida pelas mensagens escritas no WhatsApp de forma síncrona, quando os emissores e receptores estavam online e assíncronas que ocorria quando o receptor da mensagem não estava disponível, foi notória na observação das conversas dos alunos durante as discussões dos temas abordados.

Outro ponto a destacar é a possibilidade de as pessoas exporem o que pensam. Mostra que esse aplicativo pode ser uma ferramenta potencializadora quando utilizada de forma adequada ao propósito pedagógico do professor. Assim, o processo educativo por meio do ensino e da aprendizagem colaborativa é capaz de transformar o ser humano em pessoas mais emancipadas e felizes. 
V Congresso Brasileiro de Informática na Educação (CBIE 2016)

Anais dos Workshops do V Congresso Brasileiro de Informática na Educação (CBIE 2016)

A educação, para obter um bom êxito no cumprimento de suas metas gerais de transmitir tradições culturais, de renovar solidariedades e de socializar as novas gerações, necessita ser concebida por seus agentes como uma ação comunicativa. A recorrência a uma linguagem voltada ao entendimento é, por assim dizer, a condição a priori, de possibilidade da própria experiência educativa. (BOUFLEUER, 1997, p. 69).

Ao concluírem os seminários e as discussões no WhatsApp os alunos responderam a um formulário com questões objetivas e descritivas a fim de fazer uma avaliação diagnóstica da experiência. Respostas e suas respectivas análises:

\section{5 respostas}

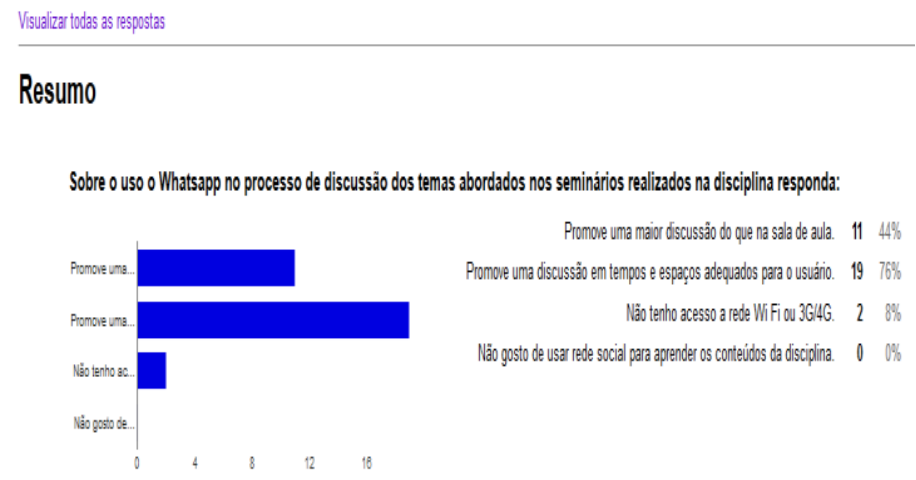

Figura 2. Respostas objetivas no formulário do google drive sobre o uso do WhatsApp.

Tabela 1. Resumo das respostas descritivas sobre o uso do WhatsApp.

"O uso desse aplicativo foi muito valioso onde todos consegui interagir e fazer trocas
de conhecimentos até quem e tímido consegui se expressa ariscar suas ideias muito
bem pensado essa ideia.
"Acredito que falamos melhor pelo WhatsApp, não gosto de aula a distância, porém em
casos como esse de discussão de conteúdos a gente se interessa mais para ler, quer
saber a opinião do outro, interagimos mais.
"Processo adequado, pois com essa inovação agregar conhecimento, faz com que
desenvolvamos o conteúdo abordado em uma ampla discussão, e com domínio dos
assuntos discutindo. E a flexibilidade de horário ótimo".

As respostas dos alunos deixam claro que a aprendizagem pode ser construída não só no espaço físico de sala de aula com nos seminários presenciais, mas também em ambientes virtuais - WhatsApp. Ressaltam também pontos negativos de seu uso, a exemplo do tempo, visto que são alunos do turno noturno e, que trabalham durante o dia; e da falta de internet para uso. É notório que a tecnologia por si só não contribui em nada para a construção do conhecimento, mas sim quando agregada a fatores externos a exemplo da motivação, temas de interesses, liberdade de expressão de ideias com ética e prazer. Para fortalecer essa análise, pode citar a pesquisa de Ferrete e Ferrete (2014) sobre o uso de tecnologia móvel que concluiram:

A inserção da tecnologia móvel em sala de aula pode colaborar para um processo de ensino e aprendizagem mais dinâmico, que estimule o 
surgimento de indivíduos autônomos na construção do saber. Todavia, faz-se necessário que a docente planeje atividades diversificadas, pensando em obter resultados significativos. (FERRETE, FERRETE, 2015, p. 852).

Assim, pode-se enfatizar que a conversação e o diálogo por meio das tecnologias móveis são formas interativas de comunicação e de inclusão social visto que muitos alunos se sentem tímidos em expressar suas opiniões e dúvidas quanto aos assuntos abordados em sala. Através dos processos de parcerias, buscas e compreensão daquilo que se desconhece, também, se aprende mais e de forma significativa.

\section{Considerações finais}

O relato de experiência abordado comprova que as tecnologias móveis agregadas ao uso pedagógico dos aplicativos disponíveis, nesse caso o WhatsApp, são potencializadoras nos processos de aprendizagens significativas. Ficou evidente na realização desse trabalho que existem alguns percalços que tornam o processo de inovação difícil de acontecer, dentre eles, a pouca disposição de tempo em trabalhar fora de sua carga horária, uma vez que esta já é bastante intensa e desvalorizada muitas vezes; o comodismo por parte de alguns profissionais da educação e a até mesmo a formação inicial e continuada do professor para enfrentar os desafios inerentes ao processo educativo.

A sociedade vive momentos de pluralização que parecem impossíveis de serem revertidos; dessa forma, não se deve conceber o mundo e a história segundo pontos de vista unitários. Compreende-se que as redes sociais, em especial aqui o WhatsApp anda lado a lado com os aparelhos portáteis e possibilitam novos processos de aprendizagens e inúmeras formas de contato com o mundo. Mas, sua utilização não é suficiente para tornar as pessoas protagonistas no ciberespaço. Ou seja, aquele que consegue ter sociabilidade a partir das tecnologias e veem a possibilidade de projetar-se na vida.

O uso do aplicativo estreitou as barreiras físicas e temporais, facilitando a troca de informações, favorecendo a aprendizagem de forma prazerosa da disciplina. Foram avanços que colocam diante dos processos de aprendizagens novos desafios e ameaças, mas, ao mesmo tempo, democratizam e facilitam o progresso individual e grupal. E, ainda permitiu uma ampliação crítica quanto ao estudo dos temas abordados.

Para a implantação dessa proposta com vistas a uma renovação na prática educativa observa-se que a formação do professor passa a ser um aspecto crítico e importante. Para esse processo de formação, é necessário que haja vivências e reflexões acerca do uso das tecnologias digitais e que sejam analisados seus limites e potencialidades, para então trabalhar com elas. Além, e principalmente, que se disponham em exercer sua profissão a fim de colaborar com uma educação pública de qualidade. Desse modo, o desafio apresentado e o feedback dos alunos em aceitar foram preponderantes para o resultado final desse trabalho. Para dar continuidade a essa experiência metodológica de aprendizagem, objetiva-se, conduzir os alunos das licenciaturas para a pesquisa e prática dessa proposta educativa com o uso das tecnologias móveis no ensino básico público municipal. 


\section{Referências}

ALENCAR et al. WhatsApp como ferramenta de apoio ao ensino. In: Anais dos Workshops do IV Congresso Brasileiro de Informática na Educação, 2015.

BRANDÃO, Carlos Rodrigues; STRECk, Danilo R. Pesquisa participante: o saber da partilha. 2. ed. Aparecida, SP: ideias \& letras, 2008.

BOUFLEUER, José P. Pedagogia da ação comunicativa: uma leitura de Habermas. Ijuí, Ed. UNIJUÍ. (Coleção Educação), 1997.

CASTRO FILHO, José Aires de et al. Um olhar sobre as atividades dos Laboratórios de Informática Educativa das escolas municipais de Fortaleza. In: Anais do XXII SBIE - XVII WIE, 2011.

FERRETE, Anne Alilma Silva Souza; FERRETE, Rodrigo Bozi. As Tecnologias móveis na formação docente. Anais dos Workshops do IV Congresso Brasileiro de Informática na Educação (CBIE 2015).

FREIRE, Paulo. Educação como prática da liberdade. 14. ed. Rio de Janeiro: Paz e Terra, 1983.

GATTI, Bernadete. Análise das políticas públicas de formação continuada no Brasil, na última década. Revista Brasileira de Educação. 57 - 69. V. 13. n. 37. jan./abr. 2008.

KENSKI, Vani Moreira. Das salas de aula aos ambientes virtuais de aprendizagem. In: Educação e tecnologias: O novo ritmo da informação. Campinas, SP: Papirus,

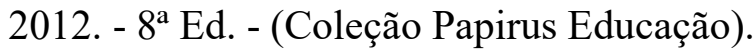

LIMA, Rodrigo R. M. de; LIMA, Wamberto J.F. de; MAIA, Dennys Leite. Formação Continuada de Professores para as TIC: Análise a Partir dos Cursos Ofertados pelo NTE-Natal. Anais do XXI Workshop de Informática na Escola (WIE 2015)

NASCIMENTO, Karla Angélica Silva do; CASTRO FILHO, José Aires de. Aprendizagem móvel e suas tecnologias: uma revisão sistemática da literatura. In: Anais dos Workshops do IV Congresso Brasileiro de Informática na Educação (CBIE 2015)

PRENSKY, Mark. Digital natives, digital immigrants. On the Horizon, v. 9, n. 5, Trad. Roberta de Moraes Jesus de Souza, 2001.

SALES, Selma Bessa \& FICHMANN, Silvia. Redes de Aprendência: uso de tecnologias digitais e formação de professores. In: Anais do XIX Workshop de Informática na Escola (WIE 2013).

SANTAELLA, Lúcia. Comunicação ubíqua: repercussões na cultura e na educação. São Paulo: Paulus, 2013. (Coleção comunicação).

TORRES, Patrícia Lupion; IRALA, Esrom Adriano F. Aprendizagem colaborativa: teoria e prática. Complexidade: redes e conexões na produção do conhecimento. Curitiba: Senar, p. 61-93, 2014.

TRIVINOS, Augusto Nibaldo Silva. Introdução à pesquisa em Ciências Sociais: A pesquisa qualitativa em educação. São Paulo: Atlas. 1995. 